thính lực và nhĩ lượng", Luận văn thạc sĩ y học, Đại hoc Y Hà Nôi.

3. Cao Minh Thành (2012), "Viêm tai dính: phân loại và xử trí", Tổng hội Y học Việt Nam, Volume (57-8) 81-87.

4. Nguyển Lễ̂ Thủy (2015), "Hình thái lâm sàng của xẹp nhî̃ qua nội soi tại bệnh viện trường đại học Y Thái Nguyên", Tạp chí khoa học và công nghệ, 134(04), 163-168.

5. Keiichi Ichimura, Kotaro Ishikawa, Ken-ichi Nakamura, Chizu Saito (2009), "Cartilage palisade tympanoplasty for adhesive otitis media", Nihon Jibiinkoka Gakkai Kaiho, 112(6): 474-9.
6. Aisha Larem, Hassan Haidar (2016), "Tympanoplasty in adhesive otitis media: A descriptive study", Epub, 126(12), 2804-2810.

7. Wenquan Li, Qiang Du, Wuqing Wang (2019), "Treatment of adhesive otitis media by tympanoplasty combined with fascia grafting catheterization", Epub, 276(10), 2721-2727.

8. Yu-mei Shen, Wen-qing Sun, Hong Shen, Yong-he Li (2010), "Tragus cartilage tympanoplasty for treatment of adhesive otitis media", Journal of Southern Medical University, 30(6): $1382-4$.

\title{
NGHIÊN CỨU TIỀN SỬ VIÊM NHIỄM ĐƯỜNG SINH DỤC VÀ MộT Số YẾU TỐ LIÊN QUAN ĐẾN VÔ SINH THỨ PHÁT DO TẮC VÒI TỬ CUNG TẠI BỆNH VIỆN PHỤ SẢN TRUNG ƯƠ'NG NĂM 2017
}

\section{TÓM TẮT}

Muc tiêu: Nghiên cứu tiền sử viêm nhiễm đường sinh dục và một số yếu tố liên quan đến vô sinh thứ phát do tắc vòi tử cung tại Bệnh viện Phụ sản Trung ương năm 2017. Đối tượng, phương pháp: Nghiên cứu hồi cứu trên 177 bểnh nhân được chẩn đoán vô sinh thứ phát do vòi tử cung được chỉ định phâuu thuật nội soi điêu trị (bao gồm cả bệnh nhân được chẩn đoán tắc vòi tử cung hoặc các bệnh lý khác của vòi tử cung nhưng không gây tắc vòi tử cung), có bệnh án đầy đủ thông tin tại Bệnh viện Phụ sản Trung ương từ tháng 1/2017 đến tháng 12/2017. Kết quả: Tỷ lệ bệnh nhân tắc vòi tử cung có tiền sử viêm âm đạo là 60,8\%; bệnh nhân tắc vòi tữ cung ở nhóm không có tiền sử viêm âm đạo là 40,2\% ( $p<0,05)$. Tỷ lệ bệnh nhân có các tiền sử liển quan ở nhóm bị tắc vòi tử cung lần lượt là: nhiễm Chlamydia (bi tắc vòi tử cung $72,7 \%$ ); đăt dụng cu tử cung (bị tắc vòi tử cung 68,6\%); phẫu thuật phụ khoa (bị tắc vòi tử cung 74,4\%); phá thai (bị tắc vòi tử cung $48,7 \%$ ); dùng thuốc tránh thai (bị tắc vòi tử cung 40\%). Kết luận: Tiền sử viêm nhiếm đường sinh dục dưới, tiền sử nhiễm Chlamydia và các tiền sử: đặt dụng cu tứ cung, phẫu thuât phu khoa vùng tiểu khung có liển quan đến vô sinh thứ phát do tắc vòi tử cung ở các bệnh nhân điều trị tại Bệnh viện Phụ sản Trung ương nằm 2017.

Tư khóa:Tiền sử liên quan, viêm nhiễm đường sinh dục, vô sinh thứ phát, tắc vòi tử cung.

\section{SUMMARY \\ ASSOCIATION BETWEEN SECONDARY}

\footnotetext{
*Bệnh viện Phụ sản Hà Nội

**Bệnh viện Phụ sản Trung ương

Chịu trách nhiệm chính: Nguyễn Duy Ánh

Email: bsanhbnhn@yahoo.com

Ngày nhận bài: 14.9.2021

Ngày phản biên khoa họ: 10.11.2021

Ngày duyệt bài: 18.11.2021
}

\section{Nguyễn Duy Ánh*, Vũ Văn Du** \\ INFERTILITY DUE TO FALLOPIAN TUBE OBSTRUCTION AND HISTORY OF GENITAL INFECTIONS AND OTHER FACTORS AT HANOI OBSTETRICS AND GYNECOLOGY HOSPITAL IN 2017}

Objectives: The study evaluated the association between secondary infertility due to fallopian tube obstruction and history of genital infections and other factors at Hanoi Obstetrics and Gynecology Hospital in 2017. Methods: Our cross-sectionsal study selected 177 patients with secondary infertility due to fallopian tube obstruction and other fallopian tube pathology. These patients were assigned to laparoscopy recanalization at Hanoi Obstetrics and Gynecology Hospital from 01/2017 to 12/2017. Results: 60,8 percent of patients with fallopian tube obstruction had prior vaginal infections $(p<0,05)$. We found other related history such as: $72,7 \%$ of patients with Chlamydia trachomatis infections had fallopian tube obstruction, $68,6 \%$ of patients using intrauterine devices, $74,4 \%$ of patients having prior pelvic surgery, $48,7 \%$ of patients used to have induced abortion, $40 \%$ of patients taking contraceptives. Conclusion: Secondary infertility due to fallopian tube obstruction in patients treated at Hanoi Obstetrics and Gynecology Hospital in 2017 is related to history of lower genital tract infections, Chlamydia trachomonas infection, prior pelvic surgery and using intrauterine devices.

Keyword: secondary infertility, fallopian tube obstruction, genital infections, related history.

\section{I. ĐẶT VẤN ĐỀ}

Vô sinh thứ phát là bệnh lý phổ biến trong sản phụ khoa hiện nay, nó gây ảnh hưởng lớn đến sức khỏe sinh sản và chất lượng cuộc sống của nhiều cặp vợ chồng. Trong đó, vô sinh do bệnh lý vòi tử cung là nguyên nhân thường gặp nhất chiếm $25-35 \%$ số trường hợp. Viêm nhiễm đường sinh dục là một trong các nguyên 
nhân chủ yếu gây vô sinh thứ phát do tắc vòi tử cung đã được thừa nhận, ngoài ra, có một số yếu tố nguy cơ khác như tiền sử phá thai, sử dụng dụng cụ tránh thai trong tử cung, thuốc tránh thai, tiền sử phẫu thuật vùng tiểu khung và vòi tử cung... cũng làm tăng tỷ lệ này [3], [6]. Vì vậy, chúng tôi tiến hành nghiên cứu này nhằm mục tiêu: Nghiên cứu tiền sử viêm nhiễm đường sinh dục và môt số yêu tố liên quan đên vô sinh thứ phát do tăc vòi tử cung tại Bệnh viện Phụ sản Trung ương năm 2017.

\section{II. ĐỐI TƯƠ'NG VÀ PHƯƠNG PHÁP NGHIÊN CỨU}

2.1. Đối tượng nghiên cứu. Các bênh nhân được chẩn đoán vô sinh thứ phát do vòi tử cung được chỉ định phẫu thuật nội soi điều trị (bao gồm cả bệnh nhân được chẩn đoán tắc vòi tử cung hoăc các bệnh lý khác của vòi tử cung nhưng không gây tắc vòi tử cung), có bệnh án đầy đủ thông tin tại Bệnh viện Phụ sản Trung ương từ tháng 1/2017 đến tháng 12/2017.

*Tiêu chuẩn lựa chọn

- Trong độ tuổi sinh đẻ.

- Có chỉ định phẫu thuật nội soi điều trị vòi tử cung.

- Có bệnh án đầy đủ thông tin nghiên cứu.

- Không mắc các bệnh lý nội khoa mãn tính.

* Tiêu chuẩn loại trừ

- Vô sinh thứ phát do các nguyên nhân không phải do vòi tử cung: do chồng, dị dạng sinh dục, vô sinh do không phóng noãn...

- Bệnh án thiếu thông tin cần thiết.

\subsection{Phương pháp nghiên cứu}

* Phương pháp nghiên cứu: Nghiên cứu hồi cứu, mô tả cắt ngang.

*Cõ̃ mẫu: Số lượng bệnh nhân được lựa chọn trong nghiên cứu này của chúng tôi là 177 bệnh nhân.

*Cách thức tiến hành: Hồi cứu số liệu của bệnh nhân có trong bệnh án của phòng Kễ hoạch tổng hợp, Bệnh viện Phụ sản Trung ương, thông tin được ghi chép lại vào phiếu thu thập thông tin theo mẫu nghiên cứu. Một số thông tin còn thiếu trong bệnh án sẽ được phỏng vấn bệnh nhân qua gọi điện thoại theo số điện thoại trong bệnh án.

\section{KẾT QUẢ NGHIÊN CỨU}

3.1. Đăc điểm chung của bênh nhân và đặc điểm vòi tử cung

Bảng 3.1. Đặc điểm chung của bệnh nhân và đặc điểm vòi tử cung

\begin{tabular}{|c|c|c|c|}
\hline \multicolumn{2}{|c|}{ Các biến số nghiên cứu } & $\mathbf{n}$ & $\%$ \\
\hline \multirow{5}{*}{ Tuổi } & $<24$ & & 8,5 \\
\hline & $25-29$ & & 22 \\
\hline & $30-34$ & & 32,8 \\
\hline & $35-40$ & & 28,8 \\
\hline & $>40$ & & 7,9 \\
\hline \multirow{2}{*}{$\begin{array}{l}\text { Nơi cư } \\
\text { trú }\end{array}$} & Thành thi & 80 & 45,2 \\
\hline & Nông thôn & 97 & 54,8 \\
\hline \multirow{3}{*}{\begin{tabular}{|c|} 
Tình trăng \\
vòi tử \\
cung \\
\end{tabular}} & Hai vòi tư cung thông & 85 & 48 \\
\hline & Tắc một bên & 28 & 15,8 \\
\hline & Tắc hai bên & 64 & 36,2 \\
\hline \multirow{4}{*}{$\begin{array}{c}\text { Vị trí tắc } \\
\text { vòi tử cung }\end{array}$} & Đoạn kẽ & 65 & 36,7 \\
\hline & Đoạn eo & 16 & 9,0 \\
\hline & Đoạn bóng & 17 & 9,6 \\
\hline & Đoan loa & 49 & 27,7 \\
\hline
\end{tabular}

Nhân xét: Độ tuổi hay gă̆p mắc vô sinh thứ phát do vòi tử cung là 30-34 tuổi. Bênh nhân ở nông thôn có tỷ lệ cao hơn ở thành thị. Có $52 \%$ bị tắc vòi tử cung trong đó vị trí hay gặp nhất là đoạn kẽ $(36,7 \%)$.

3.2. Các yếu tố liên quan đến vô sinh thứ phát do vòi tử cung

Bảng 3.2. Liên quan giữa tiền sử viêm âm đạo với vô sinh thứ phát do vòi tử cung

\begin{tabular}{|c|c|c|c|c|c|}
\hline \multirow{2}{*}{\multicolumn{2}{|c|}{ Chỉ số NC }} & \multicolumn{2}{|c|}{ Tăc vòi tử cung } & \multirow{2}{*}{ Tổng số } & \multirow{2}{*}{$\mathbf{p}$} \\
\hline & & Có & Không & & \\
\hline \multirow{2}{*}{ Viêm âm đạo } & Có & 55 & 42 & 97 & \multirow{4}{*}{$\begin{array}{l}>0,05 \\
(0,17)\end{array}$} \\
\hline & Không & 37 & 43 & 80 & \\
\hline Tống số & & 92 & 85 & 177 & \\
\hline \multicolumn{2}{|c|}{$\mathrm{p}$} & $<0,05$ & $>0,05$ & & \\
\hline
\end{tabular}

Nhận xét: Tỷ lệ bệnh nhân tắc vòi tử cung có tiên sử viêm âm đạo cao hơn tỷ lệ bệnh nhân tắc vòi tử cung ở nhóm không có tiền sử viêm âm đạo (60,8\% so với 40,2\%), sự khác biệt có ý nghĩa thống kê.

Bảng 3.3. Liên quan giữa nhiễm Chlamydia với vô sinh thứ phát do vòi tử cung

\begin{tabular}{|c|c|c|c|c|c|}
\hline \multirow{2}{*}{\multicolumn{2}{|c|}{ Chỉ số NC }} & \multicolumn{2}{|c|}{ Tắc vòi tử cung } & \multirow{2}{*}{ Tổng số } & \multirow[b]{2}{*}{$\mathbf{p}$} \\
\hline & & Có & Không & & \\
\hline Nhiềm & Có & 16 & 6 & 22 & \\
\hline Chlamydia & Không & 76 & 79 & 155 & $<0,05$ \\
\hline Tống số & & 92 & 85 & 177 & \\
\hline
\end{tabular}


Nhận xét: Tỷ lệ bệnh nhân có tiền sử nhiễm Chlamydia bị tắc vòi tử cung cao hơn có ý nghĩa thống kê so với nhóm nhiễm Chlamydia nhưng không bị tắc vòi tử cung.

Bảng 3.4. Liên quan giữa tiền sử phá thai với vô sinh thứ phát do vòi tử cung

\begin{tabular}{|c|c|c|c|c|c|}
\hline \multicolumn{2}{|c|}{ Chỉ số NC } & \multicolumn{2}{c|}{ Tắc vòi tử cung } & \multirow{2}{*}{ Tổng số } & \multirow{2}{*}{ Phông } \\
\cline { 2 - 5 } & Có & 40 & 78 & \multirow{2}{*}{$>0,05$} \\
\cline { 1 - 5 } Nạo, hút thai & Có & 38 & 45 & 99 & $(0,44)$ \\
\cline { 2 - 5 } & Không & 54 & $\mathbf{8 5}$ & $\mathbf{1 7 7}$ & \\
\hline \multicolumn{2}{|c|}{ Tống số } & $\mathbf{9 2}$ &
\end{tabular}

Nhận xét: Tỷ lệ bệnh nhân tắc vòi tử cung có tiên sử phá thai thấp hơn tỷ lệ bệnh nhân tắc vòi tử cung ở nhóm khổng có tiền sử phá thai, tuy nhiên, sự khác biệt không có ý nghĩa thống kê.

Bảng 3.5. Liên quan giữa tiền sử đặt dụng cụ tữ cung với vô sinh thứ phát do vòi tử cung

\begin{tabular}{|c|c|c|c|c|c|}
\hline \multirow{2}{*}{\multicolumn{2}{|c|}{ Chỉ số NC }} & \multirow{2}{*}{\multicolumn{2}{|c|}{ Tắc vòi tử cung }} & \multirow[b]{2}{*}{ Tổng số } & \multirow[b]{2}{*}{$\mathbf{p}$} \\
\hline & & & & & \\
\hline \multirow{2}{*}{ Đặt dụng cụ tử cung } & Có & 24 & 11 & 35 & \multirow{3}{*}{$\begin{array}{l}<0,05 \\
(0,03)\end{array}$} \\
\hline & Không & 68 & 74 & 142 & \\
\hline \multicolumn{2}{|c|}{ Tống số } & 92 & 85 & 177 & \\
\hline
\end{tabular}

Nhân xét: Tỷ lệ bệnh nhân có tiền sử đặt dụng cụ tử cung bị tắc vòi tử cung cao hơn có ý nghĩa thống kê so với nhóm đặt dụng cụ tử cung nhưng không bị tắc vòi tử cung.

Bảng 3.6. Liên quan giữa tiền sử phẫu thuật phụ khoa với vô sinh thứ phát do vòi tử cung

\begin{tabular}{|c|c|c|c|c|c|}
\hline \multicolumn{2}{|c|}{ Chỉ số NC } & \multicolumn{2}{c|}{ Tắc vòi tử cung } & \multirow{2}{*}{ Tổng số } & \multirow{2}{*}{ p } \\
\cline { 3 - 5 } & Có & Không & 43 & \multirow{2}{*}{$<0,05$} \\
\hline \multirow{2}{*}{$\begin{array}{c}\text { Tiền sử phẫu thuật } \\
\text { phụ khoa }\end{array}$} & Có & 32 & 11 & 134 & $(0,0007)$ \\
\cline { 2 - 5 } & Không & 60 & 74 & $\mathbf{1 7 7}$ & \\
\hline \multicolumn{2}{|c|}{ Tổng số } & $\mathbf{9 2}$ & $\mathbf{8 5}$ &
\end{tabular}

Nhân xét: Trong nhóm bênh nhân có tiền sử phầu thuật phụ khoa, tỷ lệ bệnh nhân bị tắc vòi tử cung cao hơn có ý nghĩa thống kê so với bệnh nhân không bị tắc vòi tử cung.

\section{BÀN LUẬN}

4.1. Bàn luân về đặc điểm chung của bênh nhân và đăc điểm vô sinh thứ phát do vò̀i tử cung. Trong nghiên cứu của chúng tôi, độ tuổi hay gặp mắc vô sinh thứ phát do vòi tử cung là 30-34 tuổi, điều này cũng phù hợp với các nghiên cứu trong nước vì đây là tuổi sinh đẻ và là thời điểm đa số bệnh nhân muốn sinh thêm con thứ hai.

Chúng tôi cũng nhận thấy: Bệnh nhân ở nông thôn có tỷ lệ bị vô sinh thứ phát do vòi tử cung cao hơn ở thành thị $(54,8 \%$ so với $45,2 \%)$, điều này có thể giải thích do ở nông thôn có một số yếu tố làm tăng tỷ lệ viêm nhiễm đường sinh dục như: Nguồn nước sinh hoạt, trình độ nhận thức và thói quen chăm sóc sức khỏe sinh sản, vệ sinh kinh nguyệt, các phong tục lạc hậu của một số địa phương cũng như thiếu các cơ sở y tế có khả năng chẩn đoán và điều trị bệnh lý phụ khoa...

Kết quả ở Bảng 3.1 cho thấy: Có $52 \%$ số bệnh nhân vô sinh thứ phát do vòi tử cung bị tắc vòi tử cung trong đó vị trí hay gặp nhất là đoạn kẽ $(36,7 \%)$, số còn lại tuy vòi tử cung thông nhưng đa số bị ứ dịch, xơ cứng, mất chức năng... Điều này cũng phù hợp với y văn vì đoạn kẽ là đoạn hẹp nhất của vòi tử cung, do đó, đoạn này dễ bị tắc nhất. Kết quả của chúng tôi cũng phù hợp với kết quả nghiên cứu của Bùi Thị Phương Nga [2].

Trong số các bệnh nhân bị tắc vòi tử cung hoàn toàn, có $36,2 \%$ tắc hoàn toàn cả hai vòi tử cung. Điều này cũng có thể giải thích do bản chất của tắc vòi tử cung trong vô sinh thứ phát ở phụ nữ Việt Nam chủ yếu do viêm nhiễm đường sinh dục, vi khuẩn lan lên gây viêm vòi tử cung và diễn biến kéo dài của phản ứng viêm sẽ gây tắc vòi tử cung. Khi bị tắc hoàn toàn hai vòi tử cung sẽ gây vô sinh thứ phát vì tinh trùng không thể đi qua vòi tử cung để thụ tinh cho trứng, các bệnh nhân này sẽ phải thụ tinh trong ống nghiệm thì mới có thể có thai.

4.2. Bàn luân về các yếu tố liên quan đến vô sinh thứ phát do vòi tử cung

* Liên quan giữa tiền sử viêm âm đạo với vô sinh thứ phát do vòi tử cung. Trong nghiên cứu của chúng tôi, tỷ lệ bệnh nhân tắc vòi tử cung có tiền sử viêm âm đạo cao hơn tỷ lệ bênh nhân tắc vòi tử cung ở nhóm không có tiền sử viêm âm đạo (60,8\% so với 40,2\%), sự khác biệt có ý nghĩa thống kê. Kết quả của chúng tôi phù hợp với Nguyễn Thị Thảo tại Bệnh viện Phụ sản Thanh Hóa trên 190 bệnh nhân vô sinh do vòi tử cung và nhóm chứng là 190 thai phụ cùng nhóm tuổi với nhóm bệnh đến khám thai định 
kỳ. Tác giả thây: nguy cơ bị vô sinh do vòi tử cung ở phụ nữ có tiền sử viêm đường sinh dục ngoài tăng gấp 2 lần $(\mathrm{OR}=2,2$; khoảng tin cậy $9551,4-3,5 ; p=0,0002)$ [4]. Cơ chế bệnh sinh là: Tác nhân gây viêm làm hủy hoại lớp niêm mạc, những tế bào biểu mô bong ra, tạo nên những ổ hoại tử và loét sâu vào lớp biểu mô để lại những thương tổn nặng nề ở vòi tử cung, hậu quả của viêm là làm hẹp lòng vòi tử cung, thành vòi tử cung dày và cứng nên nhu động giảm, mất hoăcc giảm các tế bào có lông và tế bào chế tiết, làm mất yếu tố "đẩy" của lông tế bào cũng như luồng dịch trong vòi tử cung đặc lại và chảy chậm, làm chậm sự di chuyển của trứng. Hậu quả cuối cùng là tắc vòi tử cung gây ra vô sinh thứ phát hoặc chửa ngoài tử cung...

*Liên quan giữa nhiễm Chlamydia với vô sinh thứ phát do vòi tử cung. Kết quả ở Bảng 3.3. cho thây: Tỷ lệ bệnh nhân có tiền sử nhiễm Chlamydia bị tắc vòi tử cung (16/22 chiếm $72,3 \%$ ) cao hơn có ý nghĩa thống kê so với nhóm nhiễm Chlamydia nhưng không bị tắc vòi tử cung. Kết quả của chúng tôi cũng phù hợp với kết quả của Nguyễn Thị Thảo (phụ nữ có tiền sử nhiếm Chlamydia có nguy cơ vô sinh do vòi tử cung cao gấp 6 lần phụ nữ không không có tiền sử viêm nhiềm do Chlamydia $(\mathrm{OR}=6,1$; khoảng tin cậy $=1,4-56,1 ; p=0,008$ ) so với các phụ nữ không có tiền sử bị viêm nhiếm đường sinh dục ngoài và viêm phần phụ). Đặc biệt, có tới $70 \%$ phụ nữ nhiễm Clamydia khổng có triệu chứng lâm sàng nên bệnh nhân chỉ được phát hiện khi đến khám và làm xét nghiệm, vì vậy, cần xét nghiệm Chlammydia cho tất cả các bệnh nhân viêm nhiễm phụ khoa để tránh hậu quả của bệnh [4].

*Liên quan giữa tiên sử đặt dung cư tử cung tiền sử dùng thuốc tránh thai với vô sinh thứ phát do vòi tử cung. Nghiên cứu của chúng tôi thấy: Tỷ lệ bệnh nhân có tiền sử đặt dụng cụ tử cung bị tắc vòi tử cung cao hơn có ý nghĩa thống kê so với nhóm đặt dụng cụ tử cung nhưng không bị tắc vòi tử cung. Sử dụng dụng cụ tử cung cũng có thể có mối liên quan với vô sinh do vòi tử cung. Nghiên cứu phân tích gộp của Luttjeboer gồm 5 nghiên cứu thuần tâp và 11 nghiên cứu bệnh chứng cho thấy có mổi liên quan yếu giữa tiền sử sử dụng dụng cụ tử cung với vô sinh so vòi tử cung ( $\mathrm{OR}=2.0$; khoảng tin cậy 95\%: 1,6-2,6) [5]. Theo Nguyễn Thị Thảo: Những phụ nữ có đặt dụng cụ tử cung nhiều hơn một lần có nguy cơ bị vô sinh do vòi tử cung cao gấp 3 lần so với nhóm chỉ đặt dụng cụ tử cung một lần $(O R=3,4$; khoảng tin cậy $95 \%: 1,4-$
$8,6 ; p=0,002)[4]$.

Trong nghiên cứu này, chúng tôi không thấy có sự liên quan giữa dùng thuốc tránh thai với tình trạng vô sinh do tắc vòi tử cung. Kết quả này cũng phù hợp với nghiên cứu của Nông Hồng Lê [1].

*Liên quan giữa tiền sử phẫu thuật phụ khoa với vô sinh thứ phát do vòi tử cung. Trong nhóm bệnh nhân có tiền sử phẫu thuật phụ khoa của chúng tôi, tỷ lệ bệnh nhân bị tắc vòi tử cung cao hơn có ý nghĩa thống kê so với bệnh nhân không bị tắc vòi tử cung. Theo Cao Ngọc Thành, can thiệp ngoại khoa vùng tiểu khung góp phần làm xơ hoặc gây dính các tạng ở tiểu khung hoặc thay đổi vị trí giải phẫu của vòi tử cung.. Tuy nhiên, tùy thuộc vào cơ địa người bệnh, kỹ thuật mổ, hình thức mổ (mổ mở hay mổ nội soi) mà có thể để lại hậu quả dính ở vùng tiểu khung thì đây mới là nguy cơ gây ra chửa ngoài tử cung, còn những can thiệp đơn giản như phẫu thuật nội soi trên nền cơ địa bệnh nhân không viêm dính thì ít nguy cơ gây ra tổn thương vòi tử cung [3].

*Liên quan giữa tiền sử phá thai với vô sinh thứ phát do vòi tử cung. Tỷ lệ bệnh nhân tắc vòi tử cung có tiền sử phá thai trong nghiên cứu của chúng tôi thấp hơn tỷ lệ bệnh nhân tắc vòi tử cung ở nhóm không có tiền sử phá thai, tuy nhiên, sự khác biệt không có ý nghĩa thống kê. Kết quả của chúng tôi không phù hợp với y văn trong nước và thế giới, có thể do cõ̃ mẫu của chúng tôi chưa đủ lớn. Tiền sử phá thai là một nguyên nhân có thể gây nhiễm trùng sinh dục, vì biến chứng thường gặp nhất của phá thai không an toàn là nhiễm trùng, có thể gây viêm nội mạc tử cung, viêm vòi tử cung hoặc nặng hơn là gây viêm nhiễm vùng chậu hoặc viểm phúc mạc tiểu khung. Quá trình viêm nhiễm khi bêenh nhân bị viêm vòi tử cung cấp tính hay nhiếm trùng vùng chậu có thể dẫn đến tắc vòi tử cung do dính hoặc sẹo trong lòng vòi tử cung. Kết quả của Luttjeboer, trong một nghiên cứu phân tích gộp cho thấy có sự liên quan giữa tiền sử phá thai với vô sinh do bệnh lý vòi tử cung $(\mathrm{OR}=1,7$; khoảng tin cậy $95 \%$ : $1,3-2,1)[5]$.

\section{KẾT LUÂ̂N}

Tiền sử viêm nhiễm đường sinh dục dưới, tiền sử nhiễm Chlamydia và các tiền sử: nạo hút thai, đặt dụng cụ tử cung, phẫu thuật phụ khoa vùng tiểu khung có liên quan đến vô sinh thứ phát do tắc vòi tử cung ở các bệnh nhân điều trị tại Bệnh viện Phụ sản Trung ương năm 2017. 


\section{TÀI LIÊU THAM KHẢO}

1. Nông Hồng Lê, Nguyễn Ngọc Minh (2013). Nghiên cứu vô sinh do tắc vòi tứ cung và tìm hiêu một số yếu tố ảnh hưởng tại Bệnh viện Phụ Sản Trung ương. Tạp Chí Phu sản, 11(2), 136-138.

2. Bùi Thị Phương Nga (2000), "Nghiên cứu phẫu thuật nội soi điều trị vô sinh do vòi trứng - dính phúc mạc", Luận án Tiến sỹ y học. Trường Đại học Y Dược, Thành phố Hồ Chí Minh.

3. Cao Ngọc Thanh (2011), "Vô sinh do vòi tử cung - phúc mạc", Nhà xuất bản Giáo dục.
4. Nguyễn Thị Thảo (2011), Nghiên cứu một số yếu tố nguy cơ và ảnh hưởng của vô sinh do vòi tử cung đến phụ nữ taii Thanh Hóa, Luận án Tiến sỹ, Trướng Đại học $Y$ tể công cộng.

5. Garolla A., Pizzol D., Roberto A. et al; "Practical clinical and diagnostic pathway for the investigation of the infertile coupe"; Endocrinol.,January 2021 | https://doi.org/ 10.3389/fendo.2020.591837

6. Luttjeboer F, Havada T, Hughes E et al. Tubal flushing for subfertility. Cochrane Database Syst Rev 2007(3);CD 003718.

\title{
ĐÁNH GIÁ KẾT QUẢ CỦA PHƯƠ'NG PHÁP ĐĂT NộI KHÍ QUẢN NHANH THEO TRÌNH TỰ (RSI) CHO BÊ̂NH NHÂN CẤP CỨU
}

\author{
Nguyễn Minh Hiếu*, Nguyễn Văn Chi*, Trịnh Văn Đồng*
}

\section{TÓM TẮT}

Mục tiêu: Đánh giá kết quả của phương pháp đặt nội khí quản nhanh theo trình tự so với phương pháp đẳt nội khí quản không dùng thuốc giãn cơ. Phương pháp: Nghiên cứu mô tả cắt ngang 63 tại Trung tâm cấp cứu A9 Bệnh viện Bach Mai được đặt nội khí quản theo phương pháp nhanh theo trình tự và không dùng thuốc giãn cơ. Kết quả: Nhóm bệnh lý phổ biến nhất là tiêu hóa $(33 \%)$ và hô hấp $(31 \%)$. Tỳ lệ đặt nội khí quản thành công lần đâuu theo phương pháp RSI $(88 \%)$ cao hơn so với non - RSI $(67 \%)$, sự khác biêt này có ý nghĩa thống kê $(p<0,05)$. Thới gian đặt nội khí quản của nhóm đă̆t theo phương pháp RSI (76 giây) ngắn hơn so với nhóm non - RSI (163 giây), sự khác biệt này có ý nghĩa thống kê $(p<0,05)$. Tỷ lệ tụt huyết áp trong quá trình đặt nội khí quản ở nhóm non - RSI là cao hơn so với nhóm RSI và sư khác biêt này có ý nghĩa thống kê $(p<0,05)$. Các biển cố khác tổn thương miêng, họng, đặt nội khí quản quá sâu, đặt nội khí quản vào thực quản, trào ngược, nôn, rách cuff, tut $\mathrm{SpO}_{2}$ trong quá trình thức hiên có sư khác biệt chưa có ý nghĩa thống kê giữa 2 nhóm $(p>0,05)$. Kểt luận: Phương pháp đặt nội khí quản nhanh theo trình tự với ketamine và rocuronium áp dụng với những bệnh nhân cấp cứu không có yếu tố tiên lượng đường thở khó giảm thời gian, tăng tỷ lệ thành công lân đầu và không làm tăng các biến cố trong quá trình thực hiện so với những bệnh nhân không dùng giãn cơ.

Tư khóa: đặt nội khí quản nhanh theo trình tự, an thần, giãn cơ

\section{SUMMARY \\ ASSESSMENT OF RAPID SEQUENCE INTUBATION (RSI) IN EMERGENCY PATIENTS}

\footnotetext{
*Trường Đại học Y Hà Nội

Chịu trách nhiệm chính: Nguyễn Minh Hiếu

Email: hieu1203@gmail.com

Ngày nhận bài: 13.9.2021

Ngày phản biên khoa họ: 11.11.2021

Ngày duyệt bài: 18.11.2021
}

Objective: Compare between rapid sequence intubation and intubation without using neuromuscular blocking drugs. Method: Descriptive study on 63 patients in Emergency Center, Bach Mai Hospital, who received tracheal intubation in two methods rapid sequence intubation and intubation without using neuromuscular blocking drugs. Results: The most popular diseases were digestive (33\%) and respiratory diseases (31\%). Intubations with RSI had a higher success rate on the first attempt compared to those with non-RSI ( 88 vs $67 \%, p<0,05$ ). It took less time to perform intubation with RSI compared to those with non-RSI (76s vs 163s, $\mathrm{p}<0,05$ ). Hypotension rate in non-RSI group was higher than that in RSI group $(p<0,05)$. Other complications such as mouth, throat trauma, esophageal intubation, main stem bronchial intubation, regurgitation, vomiting, cuff failure and hypoxemia in procedure did not have statistically significant difference between two group RSI and non - RSI ( $p>0,05)$. Conclusion: Rapid sequence intubation method with ketamine and rocuronium in emergency patients, who do not have difficult airway, associated with shorter time to perform endotracheal intubation, higher success rate on the first attempt but not with the risk of complications compare with intubation without neuromuscular blocking drugs.

Keywords: rapid sequence intubation, sedative, neuromuscular blocking drug

\section{I. ĐẶT VẤN ĐỀ}

Đặt nội khí quản là thủ thuật cơ bản, có ý nghĩa sống còn, là một trong những thủ thuật được thực hiện nhiều nhất trong cấp cứu. Tuy nhiên, đặt nội khí quản không phải lúc nào cũng dễ dàng và có thể gặp rất nhiều tai biến trong thực hiện như chấn thương miệng họng, gãy răng, trào ngược dịch vị... Ở các nước có nền y học phát triển, đặt nội khí quản nhanh theo trình tự (Rapid Sequence Intubation) là phương pháp phổ biến nhất, trong đó các thuốc an thần và giãn cơ được sử dụng để tạo điều kiện tối ưu cho 